20

\title{
Применение спекл-корреляционного анализа для определения скорости кровотока
}

\author{
(C) Е.А. Савченко, Е.Н. Величко \\ Санкт-Петербургский политехнический университет Петра Великого, 195251 Санкт-Петербург, Россия \\ e-mail: savchenko-spbstu@mail.ru
}

Поступила в редакцию 10.12.2019 г.

В окончательной редакции 04.03.2020 г.

Принята к публикации 28.03.2020 г.

\begin{abstract}
В настоящее время в современной диагностике микроциркуляторного русла широко применяются оптические методы, основанные на регистрации динамики спеклов. В настоящей работе приведены результаты разработки лабораторной модели малогабаритного бесконтактного спекл-датчика микроциркуляторного русла, а также методики проведения эксперимента. Приведена модель спекл-датчика для определения скорости кровотока в микроциркуляторном русле, на основе которой может быть создан прототип датчика. Представлены результаты предварительных экспериментальных исследований возможности мониторинга микроциркуляции крови в микроциркуляторном русле с использованием спекл-корреляционного анализа. В процессе проведения экспериментов была исследована группа условно здоровых волонтеров в возрасте от 18 до 24 лет. Полученные результаты коррелируют с результатами, представленными в литературе по величине определяемой скорости кровотока. Обсуждены проблемы и перспективы спекл-корреляционного мониторинга микроциркуляторного русла в лабораторных и клинических условиях.
\end{abstract}

Ключевые слова: спекл, спекл-корреляционный анализ, скорость кровотока, микроциркуляторное русло.

DOI: $10.21883 /$ OS.2020.07.49572.86-20

\section{Введение}

Капилляры отвечают за поддержание гомеостаза в организме, обеспечивая обмен кислорода, питательных веществ и продуктов обмена между тканями и кровеносным руслом [1]. Как известно, общая ёмкость капиллярного русла составляет 25-301 [2]. Когда человек находится в покое, у него задействована только четверть капиллярных петель, а при физических нагрузках - практически все капилляры [2]. В капиллярах скорость протекания крови замедляется из-за большой емкости капиллярного русла. Значение скорости для капиллярного кровотока лежит в пределах $0.1-5 \mathrm{~mm} / \mathrm{s}$, a в крупных сосудах скорость составляет 80-130 mm/s [2]. Медленная скорость микроциркуляторного кровотока обеспечивает полный обмен веществ между кровью и тканями [2].

В настоящее время актуальным вопросом современной медицины является поиск новых методов диагностики микроциркуляторного русла человека, позволяющих выявить мельчайшие изменения на ранних стадиях [13]. Как известно, параметры микроциркуляции изменяются при внутрисосудистых (нарушения реологических свойств крови и нарушение коагуляции) и внесосудистых изменениях (влияние повреждений окружающей соединительной ткани, нарушение оттока лимфы) [1]. Изменения показателей микроциркуляторного русла лежат в основе большого количества заболеваний, например сахарного диабета, хронической венозной недостаточности, заболеваний сердечно-сосудистой системы [1-4].
С развитием оптических методов, таких как лазерная допплеровская флуометрия [5], капилляроскопия, спеклколориметрия [6], интравиальная микроскопия, оптическая когерентная томография [7], появилась возможность обследовать большое количество людей в короткие сроки и контролировать состояния микроциркуляции в динамике [3]. Данные методы обладают рядом преимуществ:

- высокое пространственное и временное разрешение [8];

- неинвазивность [9];

- быстродействие [10];

- малые габариты [11].

В настоящее время расширилась практика применения спекл-корреляционного метода анализа скорости кровотока для выявления локальных расстройств микроциркуляции при различных заболеваниях [12-14].

В основе спекл-корреляционного анализа лежит определение скорости потока за счет анализа динамики интерференционной картины, образующейся при рассеянии лазерного излучения от неоднородной зондируемой области [15-19]. В случае исследования скорости кровотока в микроциркуляторном русле спекл-поле формируется за счёт рассеяния когерентного излучения на эритроцитах [15]. В работах [20] описывается ряд датчиков, основанных на данном методе и позволяющих вычислять динамические параметры. Однако некоторые из них нашли применение лишь в экспериментальной медицине из-за сложности применения их у человека, а другие связаны с использованием слишком дорогостоящей техники [21]. Например, в работе [22] представ- 


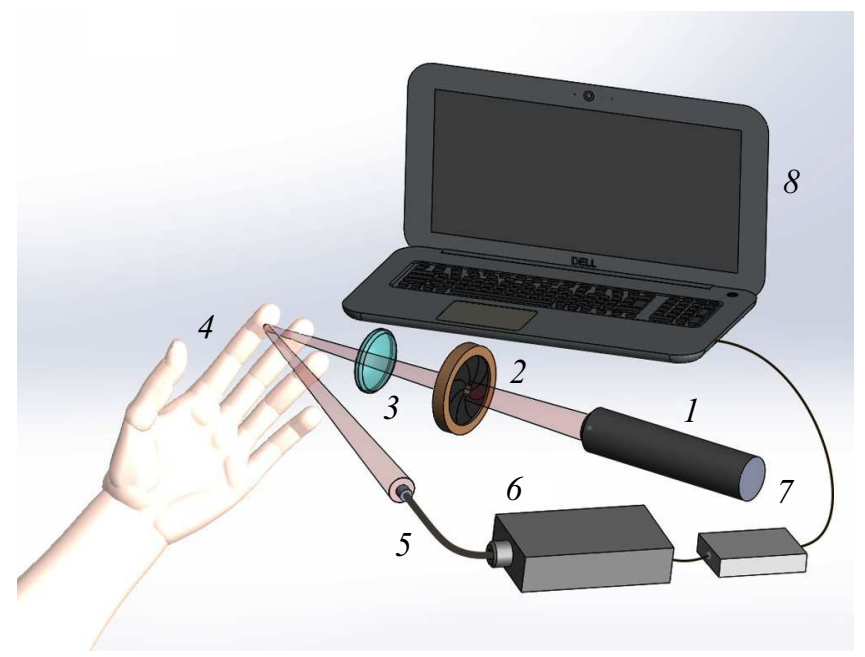

Рис. 1. Лабораторная модель оптического датчика для регистрации микроциркуляторного кровотока: 1 - полупроводниковый лазер с длиной волны $\lambda=0.65 \mu \mathrm{m}, 2-$ диафрагма, $3-$ линза, 4 - объект исследования, 5 - многомодовое оптоволокно, $6-$ фотоэлектронный умножитель, 7 - аналогоцифровой преобразователь, 8 - компьютер.

лен датчик, обладающий большими габаритами; в [23] прибор имеет высокую стоимость из-за использования дорогостоящего источника лазерного излучения; в [24] установка имеет высокую чувствительность к тремору руки, при этом возникает необходимость фиксации объекта исследования.

В связи с этим целью настоящей работы являлась разработка малогабаритного бесконтактного датчика и методики эксперимента для определения скорости протекания эритроцитов в микроциркуляторном русле, который будет лишен вышепредставленных недостатков.

\section{Методика эксперимента}

На рис. 1 представлена лабораторная модель измерительного датчика, позволяющая производить анализ скорости капиллярного кровотока в стационарных условиях.

Непрерывное когерентное лазерное излучение от одномодового полупроводникового лазера с длиной волны $0.65 \mu \mathrm{m}$ и мощностью излучения $20 \mu \mathrm{W}$ используется для зондирования участка кожи [25]. Данный лазер был выбран в качестве источника излучения, так как он имеет небольшие размеры и стабилизацию по мощности [26,27]. Контроль мощности излучения в работе осуществляется с использованием измерителя мощности перед проведением измерений [28].

Лазерное излучение проходит через диафрагму для создания однородного профиля интенсивности и далее с помощью собирающей линзы фокусируется на поверхности объекта исследования. Диаметр сфокусированного лазерного пучка в перетяжке составляет $2 \mathrm{~mm}$ [9].
При попадании света на кожу часть излучения проникает вглубь кожи и диффузно рассеивается на движущихся эритроцитах. Образующееся спекл-поле регистрируется фотоэлектронным умножителем с помощью многомодового волокна, при этом рассеянное излучение собирается в волокно с помощью коллимирующей системы $[29,30]$. Далее сигнал с фотоэлектронного умножителя поступает на аналого-цифровой преобразователь, где происходит его усиление, оцифровка, и далее сигнал передается на компьютер. При этом пространственные характеристики записи спекл-картины определяются размером апертуры фотоприемника, равным $1 \mathrm{~mm} \mathrm{в}$ диаметре, а временные характеристики определяются длительностью записи сигналов и частотой дискретизации аналого-цифровой платы. Выбор данных временных параметров производится исходя из предположений об ожидаемом уширении спектра фототока, регистрируемого фотоприемником, и теоремы Котельникова. Согласно расчетам, была выбрана частота дискретизации сигналов, равная $100 \mathrm{kHz}$. Длительность записи одного сигнала составляла $600 \mathrm{~ms}$. Характер кровотока по капилляру сложный: иногда на фоне более или менее равномерного потока крови в капилляре в течение $2-4 \mathrm{~s}$ возникает кратковременное замедление или ускорение кровотока. Это осложняет анализ скорости кровотока и затрудняет определение средней его скорости [20]. Поэтому во избежание ошибок измерения записывается 10 временных выборок в течение одного эксперимента. Соответственно длительность одного измерения составляет $1 \mathrm{~min}$.

Для обработки данных была разработана программа на языке Python, которая вычисляет автокорреляционную функцию от каждого записанного сигнала, далее строит усредненную автокорреляционную функцию, по которой определяются время корреляции и скорость кровотока. Также при расчете автокорреляционной функции вычитается статическая компонента, обусловленная рассеянием кожи [31-33].

В качестве объекта исследования в настоящей работе был выбран указательный палец правой руки.

Проведение измерений для вычисления скорости эритроцитов производится согласно следующей методике:

- измеряется для каждого волонтера давление и пульс перед проведением измерения;

- размещается неподвижно рука на оптическом столе, так чтобы исключить влияние от дрожания руки;

- подключается лабораторная модель датчика к компьютеру и запускается программа для записи и обработки данных рассеяния света;

- вводятся в компьютерную программу параметры установки, необходимые для проведения измерений и подсчета скорости кровотока, а также индивидуальные данные волонтера (пульс, давление, возраст); запускается запись сигнала рассеяния в зависимости от времени и последующее вычисление временной автокорреляционной функции рассеяния света; 


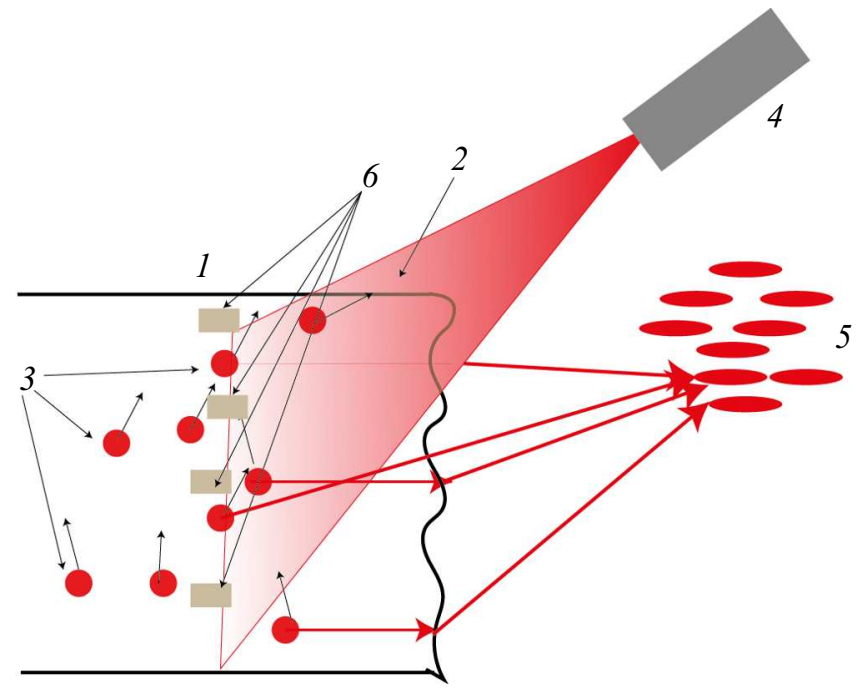

Рис. 2. Схема образования спекл-картины: $1-$ модель капилляра с эритроцитами; 2 - поверхность кожи; 3 - рассеиватели (эритроциты); 4 - зондирующее лазерное излучение; 5 - образованные спеклы; 6 - стационарные рассеиватели (кожа).

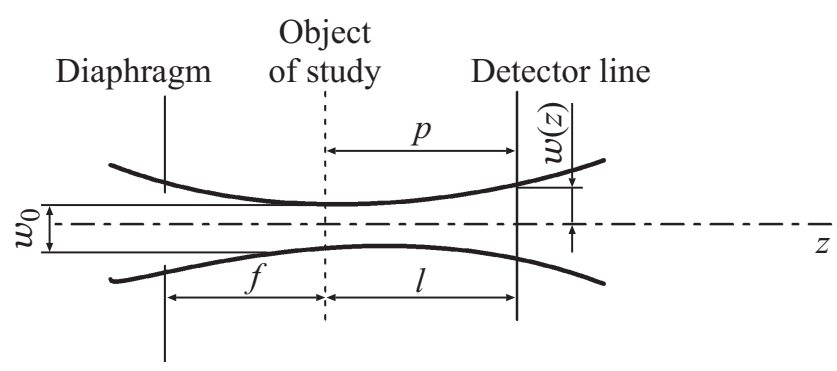

Pис. 3. Распределение амплитуды светового поля в области формирования спеклов: $\omega_{0}$ - ширина перетяжки пучка, $\omega(z)$ и $p$ - ширина и кривизна волнового фронта пучка, $l$ расстояние от рассеивающего объекта до фотоприемника.

- обрабатываются полученные данные (вычисление скорости кровотока).

\section{Обработка данных}

Для обработки полученных сигналов интенсивности обратно рассеянного светового поля используется автокорреляционный метод [12,34]. Распределение вклада в спекл-поле от эритроцитов в капилляре стремится к нормальному (в силу центральной предельной теоремы математической статистики), что позволяет применить данный метод анализа для определения скорости рассеивающих объектов $[35,36]$. На рис. 2 изображена схема образования спекл-картины, формирующаяся движущимся диффузно-рассеивающим объектом - капилляром с эритроцитами.
Параметры установки, а именно ширина и кривизна волнового фронта гауссова пучка, влияют на динамику спекл-полей.

Распределение амплитуды светового поля, освещающего рассеиватель на расстоянии $l$ (рис. 3 ) от перетяжки светового пучка, описывается выражением [34]

$$
E_{0}(\zeta)=\frac{\omega_{0}}{\omega} e^{i \frac{2 \pi z}{\lambda}} e^{-\frac{|\xi|^{2}}{\omega^{2}}} e^{i \frac{\pi|\xi|^{2}}{\lambda p}}
$$

где $\omega_{0}$ - ширина перетяжки пучка, $\lambda-$ длина волны используемого света, $\xi$ - векторная координата освещаемой точки на плоскости экрана, $\omega$ и $p-z$ зависимые ширина и кривизна волнового фронта пучка соответственно, и определяются как $[12,37]$

$$
\begin{gathered}
\omega=\omega(z)=\omega_{0}\left(1+\frac{z^{2}}{a^{2}}\right)^{1 / 2} \\
p=p(z)=z\left(1+\frac{a^{2}}{z^{2}}\right)^{1 / 2}
\end{gathered}
$$

где $a=\frac{\pi \omega_{0}^{2}}{\lambda}$.

Нормированная временная автокорреляционная функция флуктуации интенсивности рассеянного излучения $\Delta I(t)=I(t)-\langle I(t)\rangle$, где $I(t)$ и $\langle I(t)\rangle-$ интенсивность спекл-поля и её среднее значение в некоторой точке дифракционного поля на расстоянии $l$ от рассеивающего объекта, описывается следующим выражением [13]:

$$
G_{\Delta I}(\tau)=e^{-\tau^{2}\left(\frac{\vartheta^{2}}{\omega^{2}}+\frac{(\omega \pi \sigma \theta)^{2}}{(\lambda l)^{2}}\right)}
$$

где $\vartheta-$ скорость рассеивающего объекта, $l$ - расстояние от рассеивающего объекта до фотоприемника $\sigma=\frac{l}{p+1}$. Вид нормированной автокорреляционной функции представлен на рис. 4.

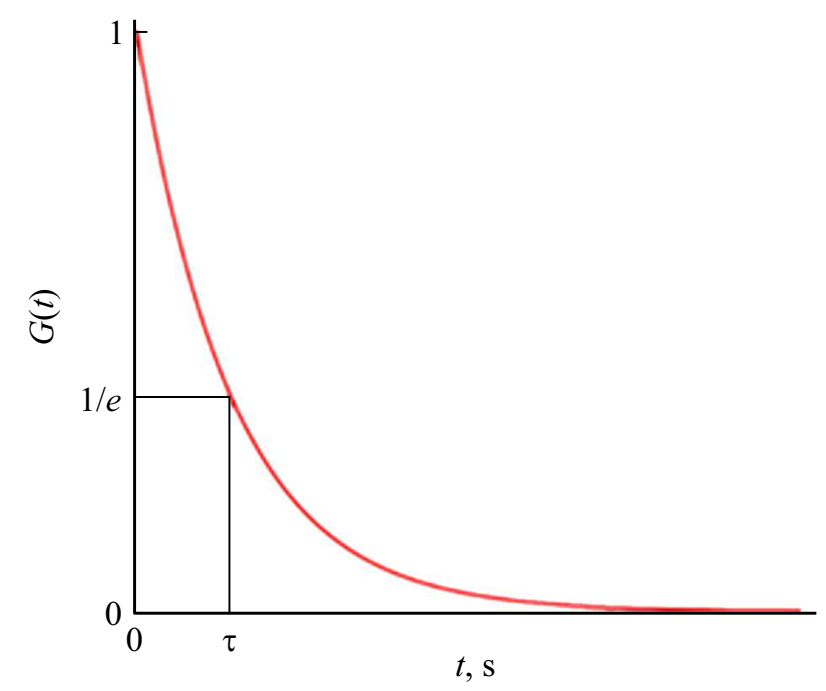

Рис. 4. Автокорреляционная функция флуктуации интенсивности излучения, рассеянного движущимися объектами. 
Обозначим за $K$ коэффициент пропорциональности, определяемый параметрами оптической схемы как

$$
K=\left(\frac{1}{\omega^{2}}+\frac{\sigma^{2}}{\Delta x^{2}}\right)^{-1 / 2}
$$

где $\Delta x=\frac{\lambda l}{\pi \omega}$. Тогда $\tau_{c}$ описывается соотношением

$$
\tau_{c}=\frac{K}{|\vartheta|},
$$

где $\vartheta-$ скорость рассеивающего объекта. Данный параметр называется временем корреляции и из экспериментальной автокорреляционной функции, как правило, определяется по уровню $1 / e$ от максимума $G(\tau)$.

Таким образом, выражение для скорости движения рассеивающего объекта имеет вид

$$
|\vartheta|=\frac{1}{\tau_{c}}\left(\frac{1}{\omega^{2}}+\frac{\sigma^{2}}{\Delta x^{2}}\right)^{-1 / 2} .
$$

Следовательно, вычисление автокорреляционной функции позволяет провести оценку средней скорости микроциркуляторного кровотока в области наблюдения по времени корреляции.

\section{Экспериментальные результаты}

Известно, что размеры и форма спеклов зависят от схемы освещения и регистрации рассеяния и не зависят от размера рассеивателей $[38,39]$, так как спекл-картина в дальней зоне дифракции получается как результат интерференции большого количества парциальных волн от многих рассеивателей. При этом средний размер спеклов $a$ в дальней зоне (в случае, если размер освещенного участка мал по сравнению с расстоянием до приемника) можно рассчитать, пользуясь следующим соотношением:

$$
a=\frac{\lambda L}{d}
$$

где $\lambda$ - длина волны используемого света, $L-$ расстояние между плоскостью рассеяния и плоскостью наблюдения, $d$ - размер освещённого участка.

В наших экспериментах эти величины составили $\lambda=650 \mathrm{~nm}, L=70 \mathrm{~mm}$ и $d=2 \mathrm{~mm}$. Поэтому авторы сочли возможным проводить измерения с учетом вышеприведенного приближения независимости спеклкартины от размера рассеивателей. Это позволило использовать в качестве модельного образца раствор родамина $6 \mathrm{G}$, частицы которого отличаются по размерам от эритроцитов в кровяном русле.

По каналу (имитатор капилляра) с контролируемой скоростью в пределах от 0 до $0.56 \mathrm{~mm} / \mathrm{s}$ пропускалась рассеивающая взвесь частиц красного красителя. Задаваемая скорость потока контролировалась с использованием платы Arduino с погрешностью не более 5\%. Имитатор капилляра представлял собой плоский капилляр толщиной $90 \mu \mathrm{m}$.
Экспериментальные и заданные значения скорости раствора

\begin{tabular}{c|c}
\hline $\begin{array}{c}\text { Экспериментальное значение } \\
\text { скорости, } \mathrm{mm} / \mathrm{s}\end{array}$ & $\begin{array}{c}\text { Заданное значение } \\
\text { скорости, } \mathrm{mm} / \mathrm{s}\end{array}$ \\
\hline $0.50 \pm 0.06$ & $0.56 \pm 0.03$ \\
$0.35 \pm 0.03$ & $0.33 \pm 0.02$ \\
$0.25 \pm 0.03$ & $0.28 \pm 0.01$ \\
$0.16 \pm 0.01$ & $0.17 \pm 0.01$
\end{tabular}

Скорость протекания родаминового потока измерялась по 10 раз для вычисления случайной погрешности.

Полученные результаты скорости потока модельной жидкости $\vartheta$, вычисленные в соответствии с формулой (7), и доверительный интервал с доверительной вероятностью 95\% представлены в таблице.

Из представленной таблицы видно, что погрешность измерения составляет порядка $10 \%$.

Результаты, полученные на модельной взвеси частиц родамина, показали, что параметры экспериментальной установки и предложенный математический аппарат позволяют получить корректные результаты вычисляемой скорости потока.

Выбранные параметры установки были также использованы для дальнейшей оценки скорости микроциркуляции крови.

После тестовых экспериментов, показавших, что корреляционный метод действительно чувствителен к изменению скорости протекания рассевающих объектов, была проведена серия экспериментов на группе условноздоровых волонтеров в возрасте от 18 до 24 лет. Измерение скорости кровотока у каждого из волонтёров производилось в течение $1 \mathrm{~min}$ на волярной поверхности (подушечки) дистальной фаланги указательного пальца кисти правой руки.

На рис. 5 представлены результаты исследования скорости кровотока у 20 волонтеров при нормальных условиях и при пережатии пальца жгутом.

Планки погрешностей, отмеченные на графике, отражают величину случайной погрешности эксперимента, рассчитанную путем вычисления среднего значения по выборке из 10 измерений, стандартного отклонения и доверительного интервала с доверительной вероятностью $95 \%$.

Полученные результаты показывают, что при пережатии пальца происходит уменьшение скорости кровотока за счет пережатия кровеносных сосудов. Как видно из полученного графика, скорость для разных волонтеров варьируется в диапазоне от 0.5 до $5 \mathrm{~mm} / \mathrm{s}$. Однако полученные значения составляют величину несколько выше типичных значений скорости капиллярного кровотока, представленных в литературных источниках. Так, в работах [21,40-42] приведены значения скорости капиллярного кровотока порядка $1-1.5 \mathrm{~mm} / \mathrm{s}$, что несколько ниже средней скорости кровотока, рассчитанной в данной работе для представленных волонтеров. 


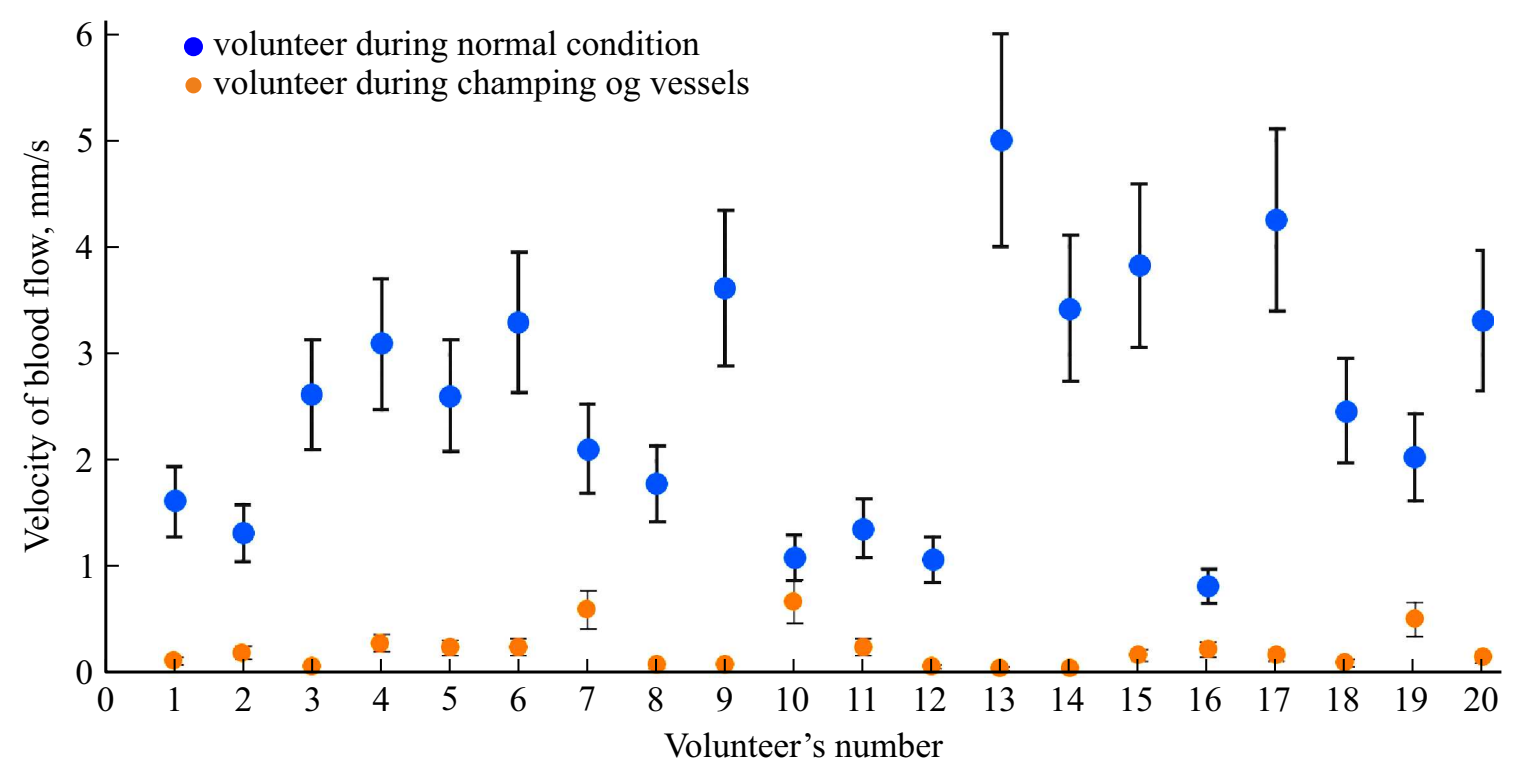

Рис. 5. Полученные результаты исследования скорости кровотока у 20 волонтеров при нормальных условиях и при пережатии пальца жгутом.

Следует отметить, что линейная скорость кровотока зависит от тонуса микрососудов, миогенных, нейрогенных и эндотелиальных факторов микроциркуляции и от изменения пассивных факторов (пульсовая волна, действие ,дыхательного насоса“). Величина линейной скорости капиллярного кровотока может формироваться в том числе на уровне более крупных и глубже расположенных по отношению к капиллярам сосудов - в мышечносодержащих артериолах. Возрастание их тонуса может приводить к увеличению линейной скорости кровотока в капиллярах кожи; это характерно преимущественно для условий вазодилатации, ее повышенной перфузии, что часто наблюдается для молодой возрастной группы [13].

Можно предположить, что полученные несколько более высокие значения скорости капиллярного кровотока характерны именно для группы волонтеров-студентов в возрасте от 18 до 24 лет, которым свойственно высокая скорость капиллярного кровоснабжения.

Однако зафиксированные различия в средней скорости капиллярного кровотока могут быть также вызваны тем, что в используемом математическом аппарате не учтены дополнительные факторы, влияющие на получаемые результаты (толщина кожи, место съема сигнала, влияние тонуса микрососудов, миогенных, нейрогенных и эндотелиальных факторов микроциркуляции и др. [42]).

Полученные предварительные результаты свидетельствуют о применимости разработанной методики, однако требуют учета в используемом математическом аппарате дополнительных факторов, которые могут влиять на линейную скорость кровотока, что планируется реализовать в дальнейших исследованиях.

\section{Заключение}

В настоящей работе предложена лабораторная модель малогабаритного бесконтактного датчика скорости кровотока и разработана методика проведения измерений с использованием данного датчика. В качестве иллюстрации, подтверждающей работоспособность лабораторной модели датчика, представлены результаты измерений скорости частиц для случая направленного движения раствора родамина. Погрешность определения скорости протекания частиц красителя составила порядка 10\%. Продемонстрирована эффективность мониторинга скорости микроциркуляторного русла в капиллярах спеклкорреляционным анализом. Натурные эксперименты были выполнены на группе волонтеров из 20 человек в возрасте от 18 до 24 лет. Полученные данные скорости попадают в диапазон значений скорости кровотока для условно-здоровых людей.

Основными достоинствами датчика являются малые габариты, мобильность установки, неинвазивность проведения исследований и невысокая стоимость компонентов.

Одним из возможных перспективных направлений применения данного метода в клинической практике является мониторинг микрогемодинамики при диабете и других заболеваниях, влияющих на микроциркуляцию, с целью диагностики и контроля осуществляемой терапии.

\section{Финансирование работы}

Исследование выполнено в рамках программы „5-1002020“ при поддержке Санкт-Петербургского политехнического университета Петра Великого. 


\section{Соблюдение этических стандартов}

Все процедуры, выполненные в исследовании с участием людей, соответствуют этическим стандартам институционального и/или национального комитета по исследовательской этике и Хельсинкской декларации 1964 г. и ее последующим изменениям или сопоставимым нормам этики.

\section{Конфликт интересов}

Авторы заявляют, что у них нет конфликта интересов.

\section{Список литературы}

[1] Лопатина А.Б. // Вестник Пермского национального исследовательского политехнического университета. 2012. № 5. C. 9-14; Lopatin A.B. // Bulletin of the Perm National Research Polytechnic University. 2012. N 5. P. 9-14.

[2] Tuchin V.V. Tissue Optics: Light Scattering Methods and Instruments for Medical Diagnosis. 2007.

[3] Виленский М.А., Агафонов Д.Н., Зимняков Д.А., Тучин В.В., Здражсевский Р.А. // Квант. электрон. 2011. T. 41. № 4. C. 324-328; Vilensky M.A., Agafonov D.N., Zimnyakov D.A., Tuchin V.V., Zdrazhevsky R.A. // Quantum Electronics. 2011. V. 41. N 4. P. 324-328.

[4] Hosking S.P.M., Bhatia R., Crock P.A, Wright I., Squance M.L., Reeves G. // Hypertension. 2009. V. 54. P. 919-950.

[5] Dremin V., Kozlov I., Volkov M., Margaryants N., Potemkin A., Zherebtsov E., Gurov I. // J. Biophotonics. 2019. V. 12. N 6. P. e201800317.

[6] Timoshina P.A., Bucharskaya A.B., Alexandrov D.A., Tuchin V.V. // J. Biomedical Photonics \& Engineering. 2017. V. 3. N 6. P. 020301.

[7] Doblhoff-Dier V., Schmetterer L., Vilser W., Garhöfer G., Gröschl M., Rainer L., Werkmeister R.M. // Biomedical Optics Epress. 2014. V. 5. N 2. P. 630.

[8] Borozdova M.A., Fedosov I.V., Tuchin V.V. // Quantum Electronics. 2015. V. 45. N 3. P. 275-282.

[9] Savchenko E.A., Gudzlovenko N.K. // J. Physics: Conference Series. 2019. V. 1326. N 1.

[10] Vilensky M.A., Agafonov D.N., Timoshina P.A., Shipovskaya O.V., Novikov P.A., Zimnyakov D.A., Tuchin V.V. // Proc. SPIE. 2011. V. 7898. P. 78989C.

[11] Zherebtsov E.A., Zharkikh E.V., Kozlov I.O., Loktionova Y.I., Zherebtsova A.I., Rafailo I.E., Rafailov E.U. // Medical Laser Applications and Laser-Tissue Interactions IX. 2019. V. 11079. P. 1107910.

[12] Лукашова О.Ф., Мокрова Д.В., Кафидова Г.А., Перевозник Д.С. // Научно-технические ведомости СПбГПУ. Физико-математические науки. 2012. № 3. С. 80; Lukashova O.F., Mokrova D.V., Kafidova G.A., Carrier D.S. // St. Petersburg State Polytechnical University J. Physics and Mathematics. 2012. N 3. P. 80.

[13] Бархатов И.В. // Клиническая медицина. 2013. Т. 91. № 11. C. 21-27; Barkhatov I.V. // Clinical Medicine. 2013. V. $91 . \mathrm{N}$ 11. P. $21-27$.

[14] Дик С.К. Лазерно-оптические методы и технические средства контроля функционального состояния биообъектов. Минск: БГУИР, 2014. 234 с.

[15] Asacura T. // Appl. Phys. 1981. V. 25. P. 179-194.
[16] Bonner R. // Appl. Opt. 1981. V. 20. N 12. P. 2097-2107.

[17] Maret G., Wolf P.E. // Zeitschrift fur Physik B: Condensed Matter. 1987. V. 65. N 4. P. 409-413.

[18] Walker S.A., Boas D.A., Gratton E. // Appl. Opt. 1998. V. 37. N 4. P. $1935-1944$.

[19] Абрамович Н.Д. // Инженерно-физический журн. 2013. T. 86. № 6. C. 1288-1295; Abramovich N.D. // Engineering Physics J. 2013. V. 86. N 6. P. 1288-1295.

[20] Чуян Е.Н., Ананченко М.Н., Трибрат Н.С. // Ученые записки Крымского федерального университета имени В.И. Вернадского. Биология. Химия. 2009. Т. 22. № 1. C. 61; Chuyan E.N., Ananchenko M.N., Tribrat N.S. // Scientific Notes of the Crimean Federal University Named After V.I. Vernadsky. Biology. Chemistry. 2009. V. 22. N 1. P. 61.

[21] Маколкин В.И. Микроциркуляция в кардиологии. М.: Визарт, 2004. 135 c.

[22] Briers J.D., Richards G., He X.W. // J. Biomed. Opt. 1999. V. 4. N 1. P. $164-175$.

[23] Дрёмин В.В., Козлов И.О., Жеребиов Е.А., Маковик И.Н., Дунаев А.В., Сидоров В.В., Крупаткин А.И. // Регионарное кровообращение и микроциркуляция. 2017. Т. 16. № 4. C. 42-49; Dremin V.V., Kozlov I.O., Zherebtsov E.A., Makovik I.N., Dunaev A.V., Sidorov V.V., Krupatkin A.I. // Regional Blood Circulation and Microcirculation. 2017. V. 16. N 4. P. 42-49.

[24] Абрамович Н.Д., Дик С.К., Василевская Л.А., Хлудеев И.И. // Докл. Белорусского государственного университета информатики и радиоэлектроники. 2019. № 5. C. 123; Abramovich N.D., Dick S.K., Vasilevskaya L.A., Khludeev I.I. // Doklady BGUIR. 2019. 2019. N 5. P. 123.

[25] Привалов В.Е., Шеманин В.Г. // Опт. и спектр. 1997. Т. 82. № 5. C. 873-875; Privalov V.E., Shemanin V.G. // Opt. Spectrosc. 1997. V. 82. N 5. P. 809-811.

[26] Nepomnyashchaya E., Zabalueva Z., Velichko E., Aksenov E. // EPJ Web of Conferences. EDP Sciences. 2017. V. 161. P. 02017.

[27] Непомнящая Э.К., Аксенов Е.Т., Величко Е.Н., Богомаз T.A. // Оптический журнал. 2015. Т. 82. № 3. С. 43-48; Nepomniashchaia E.K., Aksenov E.T., Bogomaz T.A., Velichko E.N. // J. Optical Technology. 2015. V. 82. N 3. P. $162-165$.

[28] Меркурьев С.В., Привалов В.Е., Шеманин В.Г. // Письма ЖТФ. 2000. Т. 26. № 1. C. 45-49; Merkurev S.V., Privalov V.E., Shemanin V.G. // Technical Phys. Lett. 2000. V. 26. N 1. P. 23-25.

[29] Vologdin V.A., Davydov V.V., Velichko E.N. // J. Physics: Conference Series. 2016. V. 841. N 1. P. 012095.

[30] Kotov O.I., Bisyarin M.A., Chapalo I.E., Petrov A.V. // J. Opt. Soc. Am. B. Opt. Phys. 2018. V. 35. P. 1990-1999.

[31] Temkina V., Medvedev A., Mayzel A. // J. Physics: Conference Series. 2019. V. 1236. P. 012031.

[32] Nepomnyashchaya E., Antonova E. // IEEE Int. Conf. Electr. Eng. Photonics (EExPolytech). 2018. P. 136-140.

[33] Shariaty F., Baranov M., Velichko E., Galeeva M., Pavlov V. // IEEE Int. Conf. Electr. Eng. Photonics (EExPolytech). 2019. P. $181-194$.

[34] Pusey P.N. // J. Physics D: Applied Physics. 1976. V. 9. P. 1399.

[35] Rubnikovich S.P. et al. // J. Engineering Physics and Thermophysics. 2017. V. 90. P. 1513.

[36] Fomin N. et al. // Laser Physic. 2001. V. 11. N 4. P. 525-529. 
[37] Fedosov I.V., Tuchin V.V. // Hybrid and Novel Imaging and New Optical Instrumentation for Biomedical Applications. International Society for Optics and Photonics. 2001. V. 4434. P. 192-196.

[38] Ульянов С.С. // Соросовский образовательный журн. 1999. T. 5. № 5. C. 112; Ulyanov S.S. // Soros Educational J. 1999. V. 5. N 5. P. 112.

[39] Франсон М. Оптика спеклов. М.: Наука, 1980. 171 с.

[40] Krupatkin A.I. // Human Physiology. 2014. V. 40. N 1. P. 52-57.

[41] Tuchin V.V. Handbook of Optical Biomedical Diagnostics. Bellingham, Washington: SPIE Press, 2002.

[42] Козлов В.И., Азизов Г.А., Гурова О.А., Литвин Ф.Б. Лазерная допплеровская флуорометрия в оценке состояния и расстройств микроциркуляции крови. Методическое пособие для врачей. М., 2012. Т. 32. 